\title{
Risk factors for excessive gestational weight gain in a UK population: a biopsychosocial model approach
}

\author{
S. M. Garay', L. A. Sumption', R. M. Pearson² and R. M. John ${ }^{1 *}$
}

\begin{abstract}
Background: Gestational weight gain (GWG) can have implications for the health of both mother and child. However, the contributing factors remain unclear. Despite the advantages of using a biopsychosocial approach, this approach has not been applied to study GWG in the UK. This study aimed to investigate the risk factors of excessive GWG in a UK population, employing a biopsychosocial model.

Methods: This study utilised data from the longitudinal Grown in Wales (GiW) cohort, which recruited women in late pregnancy in South Wales. Specifically, data was collected from midwife recorded notes and an extensive questionnaire completed prior to an elective caesarean section (ELCS) delivery. GWG was categorised according to Institute of Medicine (IOM) guidelines. The analysis was undertaken for 275 participants.

Results: In this population $56.0 \%$ of women had excessive GWG. Increased prenatal depression symptoms $(\operatorname{Exp}(B)=$ $1.10, p=.019)$ and an overweight $(\operatorname{Exp}(B)=4.16, p<.001)$ or obese $(\operatorname{Exp}(B)=4.20, p=.010)$ pre-pregnancy $B M I$, consuming alcohol in pregnancy $(\operatorname{Exp}(B)=.37, p=.005)$ and an income of less than $£ 18,000(\operatorname{Exp}(B)=.24, p=.043)$ and $£ 25-43,000(\operatorname{Exp}(B)=.25, p=.002)$ were associated with excessive GWG.

Conclusion: GWG is complex and influenced by a range of biopsychosocial factors, with the high prevalence of excessive weight gain in this population a cause for concern. Women in the UK may benefit from a revised approach toward GWG within the National Health Service (NHS), such as tracking weight gain throughout pregnancy. Additionally, this research provides evidence for potential targets for future interventions, and potentially at-risk populations to target, to improve GWG outcomes.
\end{abstract}

\section{Background}

The weight a woman gains during pregnancy, or gestational weight gain (GWG), can have implications for the health of both mother and child [1-3]. Inadequate GWG has been associated with higher risk of small-forgestational age (SGA) infants and preterm birth [4]. Conversely, excessive GWG is suggested to be related to higher risk of large-for-gestational age infants (LGA), macrosomia, caesarean section (CS) delivery $[4,5]$,

\footnotetext{
* Correspondence: JohnRM@cf.ac.uk

'Biomedicine Division, School of Biosciences, Cardiff University, Cardiff CF10 3AX, UK

Full list of author information is available at the end of the article
}

postpartum weight retention [6], gestational hypertension and augmentation of labour [7]. The timing of the excessive GWG in pregnancy could also be of importance, with the suggestion that there may be a critical period where GWG is most detrimental [3]. Additionally, there is recent evidence suggesting GWG is associated with childhood obesity $[3,8,9]$.

In 2009 the Institute of Medicine updated their existing guidelines on recommended GWG to incorporate the World Health Organisation (WHO) maternal prepregnancy body mass index (BMI) categories. These guidelines advise underweight women to gain $15.5-18 \mathrm{~kg}$, healthy-weight women $11.5-16 \mathrm{~kg}$, overweight women

(c) The Author(s). 2021 Open Access This article is licensed under a Creative Commons Attribution 4.0 International License, which permits use, sharing, adaptation, distribution and reproduction in any medium or format, as long as you give appropriate credit to the original author(s) and the source, provide a link to the Creative Commons licence, and indicate if changes were made. The images or other third party material in this article are included in the article's Creative Commons licence, unless indicated otherwise in a credit line to the material. If material is not included in the article's Creative Commons licence and your intended use is not permitted by statutory regulation or exceeds the permitted use, you will need to obtain permission directly from the copyright holder. To view a copy of this licence, visit http://creativecommons.org/licenses/by/4.0/ The Creative Commons Public Domain Dedication waiver (http://creativecommons.org/publicdomain/zero/1.0/) applies to the data made available in this article, unless otherwise stated in a credit line to the data. 
7-11.5 kg and obese women 5-9 kg [10]. However, a recent systematic review of over one million pregnant women demonstrated that only $30 \%$ of women obtained the recommended GWG, with 23 and 47\% having inadequate or excessive GWG, respectively [4]. It has been suggested that the prevalence of excessive GWG is increasing [11].

Pre-pregnancy overweight or obese BMI has consistently been identified as a risk factor for excessive GWG across a range of countries [12, 13]. However, evidence for other potential contributing factors is mixed. Studies have suggested a variety of contributing factors including lower socioeconomic status or social inequalities [3, 13], increased food intake and height [12], an age of over 30 years [14], hypertension [15] and parity [16]. Existing literature does not consistently employ a biopsychosocial approach, which explicitly recognises the individual and important interacting influences of biomedical, psychological and social factors on health, despite the growing consensus that this may help explain the complex nature of GWG [12]. We were unable to identify previous research examining the prevalence and risk factors of GWG in the United Kingdom (UK). This is an important oversight as, unlike other countries such as America, in the UK GWG is not tracked through pregnancy [17]. It has been reported that, in the UK pregnant women were generally unconcerned about GWG, with the suggestion that this was partly due to a lack of information from health professionals who were unsure of what to advise regarding GWG [18]. The National Institute for Health and Care Excellence (NICE) recommends that all pregnant women, in particular women with a high BMI, receive guidance on diet and physical activity but there is no specific emphasis on weight gain.

The aim of the current study was to investigate the potential biopsychosocial risk factors for excessive GWG in a UK population, utilising the Grown in Wales (GiW) cohort.

\section{Method}

\section{Participants}

The Grown in Wales cohort is a longitudinal study in the South Wales region of the United Kingdom, which has previously been described in detail [19]. Briefly, women with a term pregnancy were recruited by research midwives at the University Hospital of Wales, at the presurgical appointment for an elective caesarean section (ELCS) between 1st September 2015 and 31st November 2016. Women were invited to participate in the study if it was a singleton term pregnancy without infectious diseases or fetal anomalies. Full ethical approval was obtained via the Wales Research Ethics Committee (REC), reference 15/WA/0004.
Initially 355 women were recruited to the GiW cohort, with seven later withdrawing. The current study focused on participants who were at 37 weeks gestation or above. Participants were excluded if there was no available data on gestational weight gain, either due to missing prepregnancy BMI or delivery weight. This left 275 participants for the current analysis.

\section{Materials}

The current analysis utilised data collected from midwife recorded medical notes and an extensive questionnaire (Supplementary file 1) completed at the presurgical appointment prior to the booked ELCS.

\section{Lifestyle}

Data on lifestyle was obtained from the questionnaire. Lifestyle variables included in the analysis were exercise (defined as exercise for at least $30 \mathrm{~min}$, at least once a week), smoking (tobacco), alcohol intake and dietary patterns during pregnancy. The specific dietary patterns were Western and Health Conscious, with the method of obtaining these dietary patterns previously outlined in detail [20].

\section{Biological}

Biological variables including maternal age, parity, prepregnancy BMI and fetal sex were obtained from the questionnaire and midwife recorded notes.

\section{Psychological/mental health}

The questionnaire incorporated a measure of depression symptoms, using the Edinburgh Postnatal Depression Scale (EPDS) [21], and a measure of trait anxiety, via the trait subscale of the Spielberger State-Trait Anxiety Inventory (STAI) [22], both of which have been validated for use in the perinatal period [23, 24]. The EPDS is a 10-item questionnaire that reflects how a person has felt in the previous 7 days, with responses selected from a 4point scale. There is a maximum possible score of 30 , with a score $\geq 13$ indicative of probable depression [21, 25]. A review reported sensitivity and specificity estimates in the range of $64-100 \%$ and $73-100 \%$ respectively [23]. In the current study Cronbach's Alpha for the EPDS was .86. The trait subscale of the STAI is a 20item questionnaire that assesses anxiety levels in general, with sensitivity and specificity estimates of $80.95 \%$ and $79.75 \%$ respectively [26]. Items are rated on a 4-point scale (i.e. from "Almost never" to "Almost always"), with a maximum possible score of 80 and a score of $\geq 40$ recommended as indicative of high anxiety [27]. In our study, the Cronbach's Alpha for the STAI was found to be .91 . 


\section{Sociodemographic}

Sociodemographic information was obtained from the questionnaire and included data on ethnicity, income and education levels. Welsh Index of Multiple Deprivation (WIMD) 2014 scores were calculated from anonymised postcodes (http://wimd.wales.gov.uk). WIMD scores have a possible range of 0 to 1909 , with a lower score indicative of living in an area of higher deprivation and conversely a high score indicative of a lower deprivation area.

\section{GWG}

GWG was calculated by the researchers utilising the self-reported pre-pregnancy weight from the questionnaire and weight at delivery recorded by the research midwife. Categories within GWG were determined utilising the Institute of Medicine (IOM) recommendations for weight gain during pregnancy [10].

\section{Statistical analysis}

All analyses were undertaken utilising IBM SPSS Statistics Version 25. Normality was assessed, with all appropriate variables identified as non-parametric. KruskalWallis $\mathrm{H}$ test was employed to assess any differences in GWG across the various indications for ELCS delivery. Frequencies of participants in each IOM category were produced, both overall and split by pre-pregnancy BMI. Risk factors for excessive compared to normal GWG were assessed utilising binary logistic regression, performed utilising all potential biopsychosocial variables. Reference categories were determined by selecting the category with the largest frequency. Given the biopsychosocial nature of this research, all variables were entered simultaneously in each analysis. The binary logistic regression was then adjusted to include only those potential variables significant at $p<.15$ in the final models, similar to that utilised in existing literature [12]. Multicollinearity was assessed and found not to be present thus all identified variables were included in the regression models.

\section{Results}

Descriptive statistics for the participants eligible for inclusion in this analysis can be found in Table 1. Of these 275 participants, $42(15.3 \%)$ were in the category of inadequate GWG, 79 (28.7\%) normal GWG and 154 $(56.0 \%)$ in the excessive GWG category. The median GWG was $14.86 \mathrm{~kg}(\mathrm{IQR}=7.90)$. Frequencies of participants in each IOM category when split by prepregnancy BMI can be found in Table 2. The median weight gain of participants with an underweight prepregnancy $\mathrm{BMI}$ was $17.85 \mathrm{~kg}(\mathrm{IQR}=23.37$, range $=60.6$ $\mathrm{kg}$ ), a healthy pre-pregnancy BMI was $15.42 \mathrm{~kg}$ (IQR = 7.29 , range $=59.7 \mathrm{~kg}$ ), an overweight pre-pregnancy BMI was $15.60 \mathrm{~kg}(\mathrm{IQR}=7.70$, range $=27.4 \mathrm{~kg})$ and an obese pre-pregnancy $\mathrm{BMI}$ was $10.20 \mathrm{~kg}(\mathrm{IQR}=10.81$, range $=$ $53.0 \mathrm{~kg}$ ). All women delivered by ELCS and differences in GWG between indications for ELCS, listed in Table 1, were assessed. There was no significant difference in GWG between indications $(p=.240)$.

Analysis of potential risk factors of excessive compared to normal GWG was undertaken utilising multivariate binary logistic regression (Table 3). Variables with the strongest associations at the unadjusted multivariate level were considered for the final analysis. After assessing for multicollinearity, all potential variables were included in the final adjusted multivariate binary logistic regression (Table 4). In this analysis, an increase in EPDS total score of 1 was associated with increased odds of excessive compared to normal GWG, by a factor of 1.10. Having an overweight or obese BMI pre-pregnancy compared to normal was associated with increased odds of excessive compared to normal GWG by a factor of 4.16 and 4.20, respectively. Consuming alcohol in pregnancy was associated with decreased odds of excessive GWG by a factor of .37. A family income of less than $£ 18,000$ or $£ 25-43,000$ compared to greater than $£ 43$, 000 was associated with decreased odds of excessive GWG by a factor of .24 and .25 , respectively.

\section{Discussion}

This study aimed to investigate the risk factors of excessive GWG in a UK population. This was the first study to investigate GWG in the UK utilising a biopsychosocial approach. Within the cohort, $15.3 \%$ had inadequate GWG, 28.7\% normal GWG and 56.0\% excessive GWG. Regarding risk factors, increased depressive symptoms on the EPDS and an overweight and obese prepregnancy BMI were associated with increased risk of excessive compared to normal GWG. Conversely, an income of less than $£ 18,000$ and $£ 25-43,000$ and consuming alcohol during pregnancy were associated with decreased risk of excessive GWG.

An important finding of this research is the high prevalence of excessive weight gain of $56.0 \%$. This is considerably greater than that identified in a recent extensive systematic review, which found a worldwide prevalence of excessive GWG of $47 \%$, already worryingly high. Given the poor outcomes associated with weight gain above or below Institute of Medicine recommended guidance, this figure is a cause for concern. Current NICE guidelines within the UK state that weight gain in pregnancy should not be tracked as a matter of routine, instead recommending guidance early in pregnancy on healthy diet and physical activity rather than on healthy weight gain in general. When considering the study that concluded pregnant women in the UK lacked concern regarding GWG, partly due to unclear advice from health professionals (18), this appears to be an area that 
Table 1 Demographics for the 275 participants for whom gestational weight gain data were available

\begin{tabular}{|c|c|c|c|c|}
\hline Demographics & $\%$ (n) or median (IQR) & \multicolumn{2}{|l|}{ Demographics } & $\%(\mathrm{n})$ or median (IQR) \\
\hline Fetal sex \% (n) & & \multicolumn{2}{|l|}{ Yes } & $15.4(42)$ \\
\hline Female & $55.3(152)$ & \multicolumn{2}{|l|}{ Western dietary pattern } & $-.04(1.35)$ \\
\hline Male & $44.7(123)$ & \multicolumn{2}{|l|}{ Health conscious dietary pattern } & $.05(1.52)$ \\
\hline Gestational age (weeks) & $39.0(.0)$ & \multicolumn{2}{|l|}{ Term EPDS score } & $7.0(6.0)$ \\
\hline \multicolumn{2}{|l|}{ BMI pre-pregnancy \% (n) } & \multicolumn{2}{|l|}{ Term STAI score } & $34.0(12.0)$ \\
\hline $\begin{array}{l}\text { Normal } \\
\text { Overweight }\end{array}$ & $\begin{array}{l}51.6(142) \\
30.2(83)\end{array}$ & \multicolumn{3}{|c|}{$\begin{array}{l}\text { BMI Body Mass Index, WIMD score Welsh Index of Multiple Deprivation score, } \\
\text { EPDS Edinburgh Postnatal Depression Scale, STAI State-Trait Anxiety Inventory, } \\
\text { GCSE General Certificate of Secondary Education, A level Advanced Level. }{ }^{\text {a At }} \\
\text { any point in pregnancy }\end{array}$} \\
\hline Obese & $16.0(44)$ & \multirow{3}{*}{\multicolumn{3}{|c|}{$\begin{array}{l}\text { should be reviewed. Women in the UK may benefit from } \\
\text { a revised approach towards GWG in the various levels } \\
\text { of the NHS. }\end{array}$}} \\
\hline Maternal age at booking & $34.0(7.0)$ & & & \\
\hline Maternal ethnicity \% (n) & & & & \\
\hline Caucasian & $92.4(254)$ & \multirow{17}{*}{\multicolumn{3}{|c|}{$\begin{array}{l}\text { We previously reported a prevalence of } 14.3 \% \text { for de- } \\
\text { pression symptoms in our GiW population [19], similar } \\
\text { to other research of this type. In this study increased } \\
\text { prenatal depression symptoms were associated with in- } \\
\text { creased risk of excessive GWG. Studies on GWG do not } \\
\text { generally incorporate mental health measures. Those } \\
\text { that do often include only psychological stress rather } \\
\text { than mental health conditions such as perinatal depres- } \\
\text { sion or anxiety. A recent study that did incorporate a } \\
\text { measure of depression identified that increased depres- } \\
\text { sive symptoms on the EPDS were associated with higher } \\
\text { risk of excessive GWG, similar to our findings [28]. } \\
\text { However, another study with a measure of depression at } \\
\text { the three month booking appointment identified that } \\
\text { higher symptoms of depression were a protective factor } \\
\text { [12]. These findings highlight the importance of incorp- } \\
\text { orating measures of mood symptoms when investigating } \\
\text { GWG and suggest that the timing of mood symptoms } \\
\text { may be relevant to the risk of excessive GWG. While the } \\
\text { relationship requires further exploration, our findings }\end{array}$}} \\
\hline Other & $7.6(21)$ & & & \\
\hline Parity \% (n) & & & & \\
\hline Multiparous & $79.6(219)$ & & & \\
\hline Nulliparous & $20.4(56)$ & & & \\
\hline Indications for ELCS \% (n) & & & & \\
\hline Previous caesarean section & $55.9(147)$ & & & \\
\hline Previous pregnancy complication & $15.6(41)$ & & & \\
\hline Current pregnancy complication & $20.5(54)$ & & & \\
\hline Maternal choice & $3.4(9)$ & & & \\
\hline Maternal disorder (non-pregnancy related) & $4.6(12)$ & & & \\
\hline \multicolumn{2}{|l|}{ Highest education level \% ( $n$ ) } & & & \\
\hline Left before GCSE & $5.9(16)$ & & & \\
\hline GCSE \& Vocational & $19.9(54)$ & & & \\
\hline A-level & $11.4(31)$ & & & \\
\hline University & $33.9(92)$ & & & \\
\hline Postgraduate & $28.8(78)$ & & & \\
\hline \multicolumn{2}{|l|}{ Family income $(£) \%(n)$} & \multirow{3}{*}{\multicolumn{3}{|c|}{$\begin{array}{l}\text { Table } 2 \text { Frequencies of participants in each IOM category when } \\
\text { separated by pre-pregnancy BMI }\end{array}$}} \\
\hline$<18,000$ & $7.5(20)$ & & & \\
\hline $18-25,000$ & $8.6(23)$ & & & \\
\hline $25-43,000$ & \multirow{2}{*}{$19.4(52)$} & \multirow{2}{*}{$\begin{array}{l}\text { BMI pre-pregnancy } \\
\text { Underweight }\end{array}$} & \multicolumn{2}{|c|}{ IOM category $\quad \%(n)$} \\
\hline$>43,000$ & & & Inadequate & $33.3(2)$ \\
\hline Do not wish to say & & \multicolumn{2}{|r|}{ Normal } & $16.7(1)$ \\
\hline & $12.3(33)$ & & Excessive & $50.0(3)$ \\
\hline WIMD score & $1298.0(1230.0)$ & Normal & Inadequate & $15.5(22)$ \\
\hline Smoking in pregnancy ${ }^{\mathrm{a}} \%(n)$ & & & Normal & $39.4(56)$ \\
\hline No & $90.1(246)$ & & Excessive & $45.1(64)$ \\
\hline Yes & $9.9(27)$ & Overweight & Inadequate & $4.8(4)$ \\
\hline Alcohol in pregnancy ${ }^{a} \%$ (n) & & & Normal & $19.3(16)$ \\
\hline No & $62.6(169)$ & & Excessive & $75.9(63)$ \\
\hline Yes & $37.4(101)$ & Obese & Inadequate & $31.8(14)$ \\
\hline Exercise \% (n) & & & Normal & $13.6(6)$ \\
\hline No & $84.6(231)$ & & Excessive & $54.5(24)$ \\
\hline
\end{tabular}

Table 1 Demographics for the 275 participants for whom gestational weight gain data were available (Continued)

EPDS Edinburgh Pos, WI GCSE General Certificate of Secondary Education, A level Advanced Level. ${ }^{a}$ At

should be reviewed. Women in the UK may benefit from a revised approach towards GWG in the various levels the NHS

We previously reported a prevalence of $14.3 \%$ for depression symptoms in our GiW population [19], similar to other research of this type. In this study increased prenatal depression symptoms were associated with inthat do often include only psychological stress rather measure of depression identified that increased depressive symptoms on the EPDS were associated with higher risk of excessive GWG, similar to our findings [28]. However, another study with a measure of depression at the three month booking appointment identified that higher symptoms of depression were a protective factor [12]. These findings highlight the importance of incorporating measures of mood symptoms when investigating GWG and suggest that the timing of mood symptoms may be relevant to the risk of excessive GWG. While the Table 2 Frequencies of participants in each IOM category when separated by pre-pregnancy BM 
Table 3 Unadjusted multivariate binary logistic regression identifying significant risk factors of excessive compared to normal GWG

\begin{tabular}{|c|c|c|c|}
\hline & \multicolumn{3}{|c|}{ Excessive vs normal GWG } \\
\hline & $\mathbf{P}$ & $\operatorname{Exp}(B)$ & $95 \% \mathrm{Cl}$ \\
\hline \multicolumn{4}{|l|}{ Fetal sex } \\
\hline Female & ref & & \\
\hline Male & .575 & .79 & $.36,1.78$ \\
\hline Gestational age (weeks) & .431 & 1.27 & $.70,2.31$ \\
\hline \multicolumn{4}{|l|}{ BMI pre-pregnancy } \\
\hline Underweight & 1.000 & .00 & $.00, .00$ \\
\hline Normal & ref & & \\
\hline Overweight & $<.001$ & 4.78 & $2.01,11.34$ \\
\hline Obese & .004 & 8.76 & $2.00,38.39$ \\
\hline Maternal age at booking & .170 & 1.07 & $.97,1.19$ \\
\hline \multicolumn{4}{|l|}{ Parity } \\
\hline Multiparous & ref & & \\
\hline Nulliparous & .266 & 1.77 & $.65,4.85$ \\
\hline \multicolumn{4}{|l|}{ Highest education level } \\
\hline Left before GCSE & .262 & .29 & $.04,2.49$ \\
\hline GCSE \& Vocational & .746 & 1.21 & $.38,3.86$ \\
\hline A-level & .132 & 3.25 & $.70,15.12$ \\
\hline University & ref & & \\
\hline Postgraduate & .832 & .91 & $.37,2.24$ \\
\hline \multicolumn{4}{|l|}{ Family income } \\
\hline$<18,000$ & .264 & .34 & $.05,2.27$ \\
\hline $18-25,000$ & .332 & 2.66 & $.37,19.19$ \\
\hline $25-43,000$ & .125 & .42 & $.14,1.27$ \\
\hline$>43,000$ & ref & & \\
\hline Do not wish to say & .360 & .53 & $.13,2.08$ \\
\hline WIMD score & .802 & 1.00 & $1.00,1.00$ \\
\hline \multicolumn{4}{|l|}{ Smoking in pregnancy ${ }^{\mathrm{a}}$} \\
\hline No & Ref & & \\
\hline Yes & .231 & .37 & $.07,1.89$ \\
\hline \multicolumn{4}{|l|}{ Alcohol in pregnancy ${ }^{a}$} \\
\hline No & Ref & & \\
\hline Yes & .007 & .33 & $.15, .74$ \\
\hline \multicolumn{4}{|l|}{ Exercise } \\
\hline No & Ref & & \\
\hline Yes & .621 & 1.28 & $.49,3.34$ \\
\hline Western dietary pattern & .125 & 1.40 & $.91,2.16$ \\
\hline Health conscious dietary pattern & .475 & 1.19 & $.74,1.89$ \\
\hline Term EPDS score & .033 & 1.15 & $1.01,1.31$ \\
\hline Term STAI score & .229 & .96 & $.89,1.03$ \\
\hline
\end{tabular}

CBWC Custom birthweight centiles, BMI Body Mass Index, WIMD score Welsh Index of Multiple Deprivation score, EPDS Edinburgh Postnatal Depression Scale, STAI State-Trait Anxiety Inventory, Ref Reference category, Cl Confidence intervals, GCSE General Certificate of Secondary Education, A level Advanced Level.. ${ }^{\text {a At any }}$ point in pregnancy; $N=179$ 
Table 4 Adjusted multivariate binary logistic regression identifying significant risk factors for excessive compared to normal GWG

\begin{tabular}{|c|c|c|c|}
\hline & $P$ & $\operatorname{Exp}(B)$ & $95 \% \mathrm{Cl}$ \\
\hline \multicolumn{4}{|l|}{ BMI pre-pregnancy } \\
\hline Underweight & .716 & 1.68 & $.10,27.12$ \\
\hline Normal & ref & & \\
\hline Overweight & $<.001$ & 4.16 & $1.94,8.89$ \\
\hline Obese & .010 & 4.20 & $1.41,12.50$ \\
\hline \multicolumn{4}{|l|}{ Highest education level } \\
\hline Left before GCSE & .148 & .32 & $.07,1.49$ \\
\hline GCSE \& Vocational & .613 & 1.27 & $.50,3.23$ \\
\hline A-level & .577 & 1.39 & $.44,4.42$ \\
\hline University & ref & & \\
\hline Postgraduate & .829 & .92 & $.41,2.06$ \\
\hline \multicolumn{4}{|l|}{ Family income } \\
\hline$<18,000$ & .043 & .24 & $.06, .96$ \\
\hline $18-25,000$ & .358 & .54 & $.15,2.00$ \\
\hline $25-43,000$ & .002 & .25 & $.10, .61$ \\
\hline$>43,000$ & ref & & \\
\hline Do not wish to say & .890 & .92 & $.30,2.81$ \\
\hline \multicolumn{4}{|l|}{ Alcohol in pregnancy ${ }^{a}$} \\
\hline No & ref & & \\
\hline Yes & .005 & .37 & $.19, .74$ \\
\hline Term EPDS score & .019 & 1.10 & $1.02,1.18$ \\
\hline
\end{tabular}

BMI Body Mass Index, Cl Confidence intervals, GCSE General Certificate of Secondary Education, A level Advanced Level, Ref Reference category

${ }^{a}$ At any point in pregnancy

$\mathrm{R}^{2}=.18$ to $.25 ; N=216$

strengthen the argument to screen women for mental health problems as standard early in pregnancy in obstetric services, as this is a potentially targetable modifiable factor. This screening recommendation is also particularly important as prenatal depression is also associated with poor offspring health outcomes [29] as well as poor maternal health outcomes, for example through the association between depression and alcohol use in pregnancy [30]. This finding of an influence of a mental health factor highlights the importance of employing an overarching biopsychosocial approach to investigating complex areas such as GWG.

Pre-pregnancy BMI category was also linked to GWG in our cohort. When considering IOM categories split by pre-pregnancy BMI, it is clear that participants in all BMI categories are gaining above IOM recommendations, with excessive GWG being the most prevalent category throughout. Additionally, regarding risk factors for excessive GWG, an overweight or obese pre-pregnancy BMI was strongly associated with increased risk of excessive compared to normal GWG. Although the confidence intervals suggest this data should be interpreted with caution, reassuringly these findings are similar to existing literature in countries other than the UK, which consistently suggest that this is a risk factor for excessive weight gain $[12,13,31]$. In light of these findings it is vital to ensure all pregnant women in the UK receive advice on weight management at the earliest possible opportunity in pregnancy.

Consuming alcohol at any point in pregnancy was unexpectedly identified as a factor associated with a reduced risk of excessive weight gain. This is not a factor that has been found to be related to GWG in previous research and is challenging to interpret. Women who completely abstain from alcohol may be substituting with higher calorie non-alcoholic drinks. Alternatively, women drinking alcohol may be attempting to compensate for the alcohol by employing other improved health behaviours compared to those who do not drink alcohol [32], thus lowering the risk of excessive GWG. A third possibility is that alcohol is a proxy for another biopsychosocial factor not included in the model. This is important as the model adjusts for a number of factors, such as income and mental health, which are often linked to alcohol intake. Effectively, this approach may identify women who, in most respects, are undertaking healthy lifestyles but who very occasionally consume alcohol [32]. Finally, both an income of less than $£ 18,000$ and between $£ 25-43,000$ compared to the highest income category were found to decrease the risk of excessive weight gain. Although not a direct comparison to income, this contrasts with studies that suggested lower socioeconomic status $[3,13,33]$ increased the risk of excessive weight gain. These findings require further exploration.

A limitation of the current study is that the cohort is based in Cardiff, South Wales and as such some of the findings may not be representative of other areas of the UK, or other nationalities. Additionally, our cohort recruited women who were booked specifically for an ELCS. Given the suggested relationship between GWG and increased risk of CS delivery (4), this could have influenced our findings. However, there was no significant differences in GWG between the various indications for ELCS which reduces the risk of this influence. Due to missing data in the regression analyses, the participant number for the unadjusted model was relatively low. It is possible this has led to overfitting of the initial model. However, as this was not an issue for our final adjusted models, we feel the impact on our findings is minimised. Whilst our study incorporated data from midwife reported medical notes, the questionnaire, including the pre-pregnancy weight utilised for GWG calculations, was completed by participant self-report which, although necessary, does have inherent potential biases to 
consider. Despite these noted limitations, this research offers important insight into GWG in the UK.

\section{Conclusion}

This study identified a concerningly high prevalence of excessive GWG in our UK population, with a range of influencing factors. GWG is complex, and employing a biopsychosocial model provides a more overarching approach to identifying contributing factors. This research provides evidence for potential targets for future interventions to improve GWG outcomes. Moreover, given the poor outcomes associated with GWG, women in the UK may benefit from a revised approach towards GWG within the NHS, such as updated NICE guidelines to encourage tracking weight gain throughout pregnancy.

\section{Supplementary Information}

The online version contains supplementary material available at https://doi. org/10.1186/s12884-020-03519-1

Additional file 1:. Grown in Wales Prenatal Participant Questionnaire

\begin{abstract}
Abbreviations
A level: Advanced Level; BMI : Body mass index; CBWC: Custom birthweight centiles; $\mathrm{Cl}$ : Confidence intervals; CS : Caesarean section; ELCS : Elective caesarean section; EPDS : Edinburgh Postnatal Depression Scale; GCSE: General Certificate of Secondary Education; GiW : Grown in Wales; GWG : Gestational weight gain; IOM : Institute of Medicine; LGA : Large-forgestational age infants; MRC : Medical Research Council; NHS : National Health Service; NICE : National Institute for Health and Care Excellence; REC : Research Ethics Committee; STAI : State-Trait Anxiety Inventory; UK : United Kingdom; WHO : World Health Organisation; WIMD : Welsh Index of Multiple Deprivation
\end{abstract}

\section{Acknowledgements}

The authors are grateful to the participants of the Grown in Wales study and the research midwives, Nicola Savory and Anouk Ridgway, who contributed to the present study. We additionally thank Dr. Anna Janssen for her involvement in the design of the Grown in Wales study, Dr. Richard Penketh for supporting the recruitment of participants and additional members of the Pregnancy Research Epigenetic Group for helping with data entry.

\section{Authors' contributions}

RMJ takes full responsibility for the work as a whole, including the study design, access to data and the decision to submit and publish the manuscript. Study design RMJ; data analysis SMG, LAS, RMP; manuscript RMJ and SMG. All authors have read and approved the final manuscript.

\section{Funding}

The Grown in Wales study was funded by Medical Research Council (MRC) grant (MR/M013960/1); SMG was supported by a GW4 BioMed MRC DTP PhD studentship (MR/N013794/1); LAS was supported by GW4 SWBio BBSRC DTP PhD studentship (BB/M009122/1).

\section{Availability of data and materials}

For this specific study, there is a danger that sharing participant data might reveal participant identity due to the nature of the data, the specific recruitment dates and unique route of recruitment. The datasets used and analysed during the current study will therefore not be made publically available but will be available from the corresponding author on reasonable request.

\section{Ethics approval and consent to participate}

Full ethical approval for the GiW Study cohort was obtained from the Wales Research Ethics Committee REC reference 15/WA/0004. Research was performed in line with the principles of the Declaration of the Helsinki as revised in 2008. Written informed consent was obtained from all the participants at recruitment.

\section{Consent for publication}

Not applicable.

\section{Competing interests}

None.

\section{Author details}

${ }^{1}$ Biomedicine Division, School of Biosciences, Cardiff University, Cardiff CF10 $3 A X$, UK. ${ }^{2}$ Centre for Academic Mental Health, Population Health Sciences, Bristol Medical School, University of Bristol, Oakfield House, Bristol BS8 2BN, UK.

Received: 6 March 2020 Accepted: 22 December 2020

Published online: 10 January 2021

\section{References}

1. Voerman E, Santos S, Inskip H, Amiano P, Barros H, Charles M-A, et al. Association of Gestational Weight Gain with Adverse Maternal and Infant Outcomes. JAMA. 2019;321(17):1702-15.

2. Santos $\mathrm{S}$, Voerman $\mathrm{E}$, Amiano P, Barros H, Beilin L, Bergström A, et al. Impact of maternal body mass index and gestational weight gain on pregnancy complications: an individual participant data meta-analysis of European, north American and Australian cohorts. BJOG Int J Obstet Gynaecol. 2019;126(8):984-95.

3. Campbell EE, Dworatzek PD, Penava D, De Vrijer B, Gilliland J, Matthews Jl, et al. Factors that influence excessive gestational weight gain: moving beyond assessment and counselling. J Matern Fetal Neonatal Med. 2016; 29(21):3527-31.

4. Goldstein RF, Abell SK, Ranasinha S, Misso M, Boyle JA, Black MH, et al. Association of gestational weight gain with maternal and infant outcomes: a systematic review and meta-analysis. Jama. 2017;317(21):2207-25.

5. Rogozińska E, Zamora J, Marlin N, Betrán AP, Astrup A, Bogaerts A, et al. Gestational weight gain outside the Institute of Medicine recommendations and adverse pregnancy outcomes: analysis using individual participant data from randomised trials. BMC Pregnancy Child. 2019;19(1):322.

6. Siega-Riz AM, Viswanathan M, Moos M-K, Deierlein A, Mumford S, Knaack J, et al. A systematic review of outcomes of maternal weight gain according to the Institute of Medicine recommendations: birthweight, fetal growth, and postpartum weight retention. Am J Obstet Gynecol. 2009;201(4):339 e1e14.

7. Crane JM, White J, Murphy P, Burrage L, Hutchens D. The effect of gestational weight gain by body mass index on maternal and neonatal outcomes. J Obstet Gynaecol Can. 2009;31(1):28-35.

8. Nehring I, Lehmann S, Von Kries R. Gestational weight gain in accordance to the IOM/NRC criteria and the risk for childhood overweight: a metaanalysis. Pediatr Obes. 2013;8(3):218-24.

9. Tie H-T, Xia Y-Y, Zeng Y-S, Zhang Y, Dai C-L, Guo JJ, et al. Risk of childhood overweight or obesity associated with excessive weight gain during pregnancy: a meta-analysis. Arch Gynecol Obstet. 2014;289(2):247-57.

10. Medicine lo. In: Rasmussen KM, Yaktine AL, editors. Weight gain during pregnancy: reexamining the guidelines. Washington: National Academy of Sciences; 2009.

11. Gavard JA, Artal R. The association of gestational weight gain with birth weight in obese pregnant women by obesity class and diabetic status: a population-based historical cohort study. Matern Child Health J. 2014;18(4): 1038-47.

12. Heery E, Kelleher CC, Wall PG, McAuliffe FM. Prediction of gestational weight gain-a biopsychosocial model. Public Health Nutr. 2015;18(8):148898.

13. Kowal C, Kuk J, Tamim H. Characteristics of weight gain in pregnancy among Canadian women. Matern Child Health J. 2012;16(3):668-76.

14. Chasan-Taber L, Schmidt MD, Pekow P, Sternfeld B, Solomon CG, Markenson $G$. Predictors of excessive and inadequate gestational weight gain in Hispanic women. Obesity. 2008;16(7):1657-66.

15. Fraga ACSA, Theme Filha MM. Factors associated with gestational weight gain in pregnant women in Rio de Janeiro, Brazil, 2008. Cadernos Saude Publica. 2014;30:633-44. 
16. Brawarsky P, Stotland N, Jackson R, Fuentes-Afflick E, Escobar G, Rubashkin $\mathrm{N}$, et al. Pre-pregnancy and pregnancy-related factors and the risk of excessive or inadequate gestational weight gain. Int J Gynecol Obstet. 2005; 91(2):125-31.

17. NICE PHG. National Institute Health and care excellence weight management before, during and after pregnancy. 2010.

18. Olander EK, Atkinson L, Edmunds JK, French DP. The views of pre-and postnatal women and health professionals regarding gestational weight gain: an exploratory study. Sex Reprod Healthc. 2011;2(1):43-8.

19. Janssen AB, Savory KA, Garay SM, Sumption L, Watkins W, Garcia-Martin I, et al. Persistence of anxiety symptoms after elective caesarean delivery. BJPsych Open. 2018;4(5):354-60.

20. Garay SM, Savory KA, Sumption L, Penketh R, Janssen AB, John RM. The grown in Wales study: examining dietary patterns, custom birthweight centiles and the risk of delivering a small-for-gestational age (SGA) infant. PLoS One. 2019;14(3):e0213412.

21. Cox JL, Holden JM, Sagovsky R. Detection of postnatal depression: development of the 10-item Edinburgh postnatal depression scale. Br J Psychiatry. 1987;150(6):782-6.

22. Spielberger C, Gorsuch R, Lushene R, Vagg P, Jacobs G. Manual for the state-trait anxiety inventory (Palo Alto, Consulting psychologists press). Inc. 1983.

23. Kozinszky Z, Dudas RB. Validation studies of the Edinburgh postnatal depression scale for the antenatal period. J Affect Disord. 2015;176:95-105.

24. Meades $R$, Ayers $S$. Anxiety measures validated in perinatal populations: a systematic review. J Affect Disord. 2011;133(1-2):1-15.

25. Matthey S, Henshaw C, Elliott S, Barnett B. Variability in use of cut-off scores and formats on the Edinburgh postnatal depression scale-implications for clinical and research practice. Arch Women's Mental Health. 2006;9(6):30915.

26. Grant K-A, McMahon C, Austin M-P. Maternal anxiety during the transition to parenthood: a prospective study. J Affect Disord. 2008;108(1-2):101-11.

27. Barnett $B$, Parker $G$. Professional and non-professional intervention for highly anxious primiparous mothers. Br J Psychiatry. 1985;146(3):287-93.

28. Hecht LM, Schwartz N, Miller-Matero LR, Braciszewski JM, Haedt-Matt A. Eating pathology and depressive symptoms as predictors of excessive weight gain during pregnancy. J Health Psychol. 2020:1359105320913934.

29. Smith A, Twynstra J, Seabrook JA. Antenatal depression and offspring health outcomes. Obstet Med. 2020;13(2):55-61.

30. Brown R, Dakkak H, Gilliland J, Seabrook JA. Predictors of drug use during pregnancy: the relative effects of socioeconomic, demographic, and mental health risk factors. J Neonatal-Perinatal Med. 2019;12(2):179-87.

31. Garmendia ML, Mondschein S, Matus O, Murrugarra R, Uauy R. Predictors of gestational weight gain among Chilean pregnant women: the Chilean maternal and infant nutrition cohort study. Health Care Women Int. 2017; 38(8):892-904.

32. Melotti R, Heron J, Hickman M, Macleod J, Araya R, Lewis G. Adolescent alcohol and tobacco use and early socioeconomic position: the ALSPAC birth cohort. Pediatrics. 2011;127(4):e948-e55.

33. Cheney K, Berkemeier S, Sim KA, Gordon A, Black K. Prevalence and predictors of early gestational weight gain associated with obesity risk in a diverse Australian antenatal population: a cross-sectional study. BMC Pregnancy Child. 2017;17:296.

\section{Publisher's Note}

Springer Nature remains neutral with regard to jurisdictional claims in published maps and institutional affiliations.

Ready to submit your research? Choose BMC and benefit from:

- fast, convenient online submission

- thorough peer review by experienced researchers in your field

- rapid publication on acceptance

- support for research data, including large and complex data types

- gold Open Access which fosters wider collaboration and increased citations

- maximum visibility for your research: over $100 \mathrm{M}$ website views per year

At $\mathrm{BMC}$, research is always in progress.

Learn more biomedcentral.com/submissions 